\title{
ANÁLISE DOS EFEITOS DE GEADAS NA COBERTURA VEGETAL DO MUNICÍPIO DE CÂNDIDO MOTA - SP, BRASIL, POR MEIO DE ÍNDICES DE VEGETAÇÃO
}

\author{
ANALYSIS OF THE EFFECT OF FROST IN THE LAND COVER IN CÂNDIDO \\ MOTA - SP, BRAZIL, BY MEANS OF VEGETATION INDICES
}

\begin{abstract}
ANÁLISIS DE LOS EFECTOS DE HELADAS EN LA CUBIERTA VEGETAL DEL MUNICIPIO DE CÂNDIDO MOTA - SP, BRASIL, POR MEDIO DE ÍNDICES DE VEGETACIÓN
\end{abstract}

\author{
Julio Cesar Demarchi - Universidade Estadual Paulista - Ourinhos - São Paulo - Brasil \\ julio.demarchi@gmail.com
}

Edson Luís Piroli - Universidade Estadual Paulista - Ourinhos - São Paulo - Brasil
elp@ourinhos.unesp.br

\section{Resumo}

As geadas afetam negativamente a produção agrícola e, consequentemente, a sociedade e a economia por meio da diminuição da produtividade e do aumento do preço dos alimentos. Este trabalho teve como objetivo analisar os efeitos das geadas ocorridas no município de Cândido Mota, São Paulo (SP) em 28/06 e 04/08/2011 por meio dos índices de vegetação NDVI (Índice de Vegetação por Diferença Normalizada) e NDWI (Índice de Água por Diferença Normalizada), verificar a influência da altitude na intensidade do fenômeno climático, seus efeitos na cobertura vegetal e em algumas culturas agrícolas, além de avaliar a eficácia destes índices na detecção das alterações provocadas pelas geadas na cobertura vegetal. As "imagens diferença" de NDVI e $\mathrm{NDWI}$, de datas anteriores e posteriores à primeira e à segunda geada e as análises zonais, apontaram que as principais culturas agrícolas afetadas foram: milho safrinha, aveia, trigo e cana-de-açúcar. 0 efeito das geadas foi maior nas altitudes médias (400 a $500 \mathrm{~m}$ ). 0s índices NDVI e NDWI tiveram desempenho semelhante na detecção dos efeitos das geadas sobre a cobertura vegetal, embora tenham sido concebidos para diferentes finalidades.

Palavras-chave: NDVI, NDWI, altitude, Sensoriamento Remoto.

\section{Abstract}

Frosts affect negatively the agricultural production and, consequently, the society and economy by decreasing productivity and creasing in food prices. This paper aimed to analyze the effects of the frosts occurred on June 28th and on August 4th, 2011, in the city of Cândido Mota, São Paulo state, by means of vegetation indices, such as Normalized Difference Vegetation Index (NDVI) and Normalized Difference Water Index (NDWI). Also, it verifies the influence of altitude in the intensity of this climatic phenomenon and their effects in vegetation cover and some agricultural crops, and evaluates the effectiveness of these indices in detecting changes caused by frosts in vegetation cover. The NDVI and NDWI "difference images" of previous and posterior dates to the first and the second frosts and the zonal analysis pointed out that the main affected crops were: winter corn, barley, wheat and sugarcane. The effect of the frosts was higher in medium altitudes (400 to $500 \mathrm{~m}$ ). The indices NDVI and NDWI had similar performance in detecting the effect of frosts in vegetation cover, although they have been designed for different purposes.

Keywords: NDVI, NDWI, altitude, remote sensing. 
Artigo

\section{Resumen}

Las heladas afectan negativamente la producción agrícola y, consecuentemente, la sociedad y la economía por medio de la disminución de la productividad y del aumento del precio de los alimentos. Este trabajo tuvo como objetivo analizar los efectos de las heladas ocurridas en el municipio de Cândido Mota, São Paulo (SP), en 28 de junio y 4 de agosto de 2011 por medio de los índices de vegetación NDVI (Índice de Vegetación por Diferencia Normalizada) y NDWI (Índice de Agua por Diferencia Normalizada), verificar la influencia de la altitud en la intensidad del fenómeno climático, sus efectos en la cubierta vegetal y en algunos cultivos agrícolas, además de evaluar la eficacia de estos índices en la detección de los cambios causados por las heladas en la cubierta vegetal. Las "imágenes diferencia" de NDVI y NDWI, de fechas anteriores y posteriores a la primera y a la segunda helada y los análisis zonales, apuntaron que los principales cultivos agrícolas afectados fueron: maíz de invierno, avena, trigo y caña de azúcar. El efecto de las heladas fue mayor en las altitudes medias (400 a $500 \mathrm{~m})$. Los índices NDVI y NDWI tuvieron desempeño similar en la detección de los efectos de las heladas sobre la cubierta vegetal, aunque hayan sido concebidos para propósitos distintos.

Palabras clave: NDVI, NDWI, altitud, teledetección

Introdução

A geada é definida como um processo em que os cristais de gelo são depositados sobre uma superfície exposta, devido à sua temperatura ter caído até a temperatura do ponto de orvalho do ar, ou seja, em vez de a umidade (vapor de água) existente no ar se condensar sob a forma líquida, ela passa diretamente do estado de vapor ao de cristais de gelo, constituindo o orvalho congelado. Pode ocorrer também quando o ar está muito seco e o vento muito frio. Neste caso ocorre o congelamento dos tecidos vegetais sem que haja formação de gelo. Este fenômeno é conhecido por geada negra (Mota, 1975).

Os vegetais possuem diferentes graus de resistência às geadas, e os principais danos às culturas agrícolas ocorrem em razão do congelamento dos seus tecidos, ou seja, pela formação de cristais de gelo dentro das células ou devido ao congelamento extracelular e consequente desidratação do seu protoplasma (Mota, 1975).

Os efeitos dos fenômenos de geada na cobertura vegetal e na produção agrícola podem ser avaliados e mensurados a partir dos índices de vegetação, entre eles o Índice de Vegetação por Diferença Normalizada (NDVI), desenvolvido por Rouse et al. (1973) a partir da razão normalizada entre as bandas do vermelho e infravermelho próximo.

De acordo com Jensen (2009), o NDVI é importante porque as mudanças sazonais e interanuais no desenvolvimento da atividade da vegetação podem ser monitoradas e pelo fato de muitos ruídos multiplicativos das imagens de satélite serem atenuados pela razão entre as bandas. 
Rafaelli et al. (2006) usaram imagens NDVI extraídas do satélite MODIS/TERRA para analisar a redução do vigor vegetativo e da atividade fotossintética da vegetação decorrentes de geadas na cobertura vegetal do estado do Paraná (PR), Brasil, e nas lavouras de café da região de Cornélio Procópio - PR. Nessas últimas, o valor médio de NDVI reduziu de 0,58 para 0,48 entre os dias 11 e 27 de julho de 2000, resultado de geadas consecutivas, uma delas de intensidade severa.

O Índice de Água por Diferença Normalizada (Normalized Difference Water Index - NDWI) foi proposto por Gao (1996) como alternativa ao NDVI, índice de vegetação mais conhecido e utilizado. O índice utiliza dois canais do infravermelho, centrados nos comprimentos de onda 0,86 $\mu \mathrm{m}$ e 1,24 $\mu \mathrm{m}$, e baseia-se no princípio de que a absorção da radiação solar pela umidade do dossel das plantas é desprezível no canal 0,86 $\mu \mathrm{m}$ e fraca no canal $1,24 \mu \mathrm{m}$, devido ao espalhamento da radiação solar, embora ambos os canais atuem sobre a mesma profundidade de dossel.

O NDWI é menos sensível aos efeitos de espalhamento atmosférico que o NDVI e, a exemplo deste índice, não remove totalmente o efeito de reflectância do solo. Porém, medidas realizadas por Gao (1996) em campo e laboratório mostraram que o NDWI é mais sensível às variações no conteúdo de água no dossel e em folhas empilhadas que o NDVI, que satura em condições de Índices de Área Foliar elevados.

Para suprir a falta de sensores remotos centrados no comprimento de onda $1,24 \mu \mathrm{m}$, Jackson et al. (2004) utilizaram a banda $5(1,55-1,75 \mu \mathrm{m})$ dos satélites Landsat 5 TM e Landsat 7 ETM+, além da banda 4, para gerar imagens NDWI de áreas de cultivo de soja e milho na bacia experimental Walnut Gulch, Iowa, Estados Unidos. Os autores geraram também índices NDVI das imagens Landsat de junho e julho de 2002 e fizeram análises em campo. A partir do relacionamento entre esse conjunto de dados, foram elaboradas funções para determinar o conteúdo de água da vegetação e os índices NDVI e NDWI. Os autores verificaram que o NDWI foi mais eficiente que o NDVI na estimativa do conteúdo de água na cultura do milho, uma vez que se mostrou mais sensível às mudanças fisiológicas do cultivo.

De acordo com Ceccato et al. (2002), as limitações do índice NDVI na estimativa do conteúdo de água na planta e no relacionamento entre teor de clorofila e conteúdo de água se devem aos seguintes pressupostos, a nível de folha: cada espécie vegetal possui características próprias em 
termos de teor de clorofila e conteúdo de água; o decréscimo no teor de clorofila não implica na redução no conteúdo de água e vice-versa.

A topografia possui influência na acumulação e escoamento do ar frio no terreno, podendo afetar severamente as lavouras em noites de geada. Os terrenos mais propícios à ocorrência de geadas são as encostas elevadas com declividade superior a $10 \%$, os espigões e as vertentes de configuração convexa com mais de $5 \%$ de declive. A maior frequência de geadas nos terrenos baixos e depressões se deve à produção do orvalho em maior quantidade em função da concentração do ar frio e de sua maior densidade (Mota, 1975).

Petsch e Bueno (2013) avaliaram a influência das geadas ocorridas em julho de 2000 na cobertura vegetal do município de Maringá - PR por meio do índice de vegetação NDVI aplicado nas imagens do satélite Landsat-5 de 14/06 e 16/07/2000. As imagens NDVI foram fatiadas nas classes "folhas verdes", "intermediária” e "folhas secas", e os resultados apontaram a redução, em área, da vegetação com folhas verdes e o aumento na área ocupada pelas classes "intermediária" e "folhas secas" após a ocorrência das geadas, sobretudo nas baixas vertentes e fundos de vale, o que comprova a maior incidência de geada nesses compartimentos de relevo.

Os prejuízos causados pelas geadas, consideradas sua intensidade e frequência, têm consequências econômicas e alimentares diretas decorrentes do aumento dos preços e da redução da qualidade dos produtos agropecuários, mas os produtores rurais são os principais prejudicados pelas perdas parciais ou totais de suas lavouras, o que pode resultar no abandono do campo e das atividades agrícolas ou em transformações nos modelos de exploração agrícola.

As fortes geadas de 1975, por exemplo, dizimaram totalmente o parque cafeeiro do norte do Paraná e constituíram fator determinante do abandono da cafeicultura e adoção de novos cultivos agrícolas no estado, além de impulsionar o processo de modernização da agricultura, ampliar a concentração fundiária e expropriar os trabalhadores rurais do café (parceiros, arrendatários, meeiros e pequenos proprietários) (Serra, 2001).

O município de Cândido Mota, área de estudo deste trabalho, está localizado na porção Centro-Oeste do Estado de São Paulo, entre as coordenadas geográficas $22^{\circ} 40^{\prime} 24^{\prime \prime} \mathrm{S}$ a $22^{\circ} 56^{\prime} 41^{\prime \prime S}$ e $50^{\circ} 15^{\prime} 55^{\prime \prime} \mathrm{W}$ a $50^{\circ} 34^{\prime} 40^{\prime \prime} \mathrm{W}$ (Figura 01). 
De acordo com o Censo Demográfico 2010, a população do município é de 29.884 habitantes, sendo $94 \%$ urbana e $6 \%$ rural (IBGE, 2010). Segundo a classificação climática de Köppen-Geiger, o clima do município de Cândido Mota é do tipo "Am”, tropical chuvoso com inverno seco cuja precipitação do mês mais seco é inferior a $60 \mathrm{~mm}$, a temperatura média do mês mais frio é igual ou superior a $18^{\circ} \mathrm{C}$ e a temperatura média do mês mais quente é igual ou superior a $22^{\circ} \mathrm{C}$. A precipitação média anual é de $1.451,2 \mathrm{~mm}$, sendo janeiro o mês mais chuvoso $(212,2 \mathrm{~mm})$ e agosto o mês mais seco $(44,8 \mathrm{~mm})$. A estação chuvosa ocorre de outubro a março e a estação seca, de abril a setembro. A temperatura média anual é de $22,4^{\circ} \mathrm{C}$, sendo $18,8^{\circ} \mathrm{C}$ a temperatura média do mês mais frio (julho) e $25,3^{\circ} \mathrm{C}$ a temperatura média do mês mais quente (fevereiro) (Miranda et al., 2005).
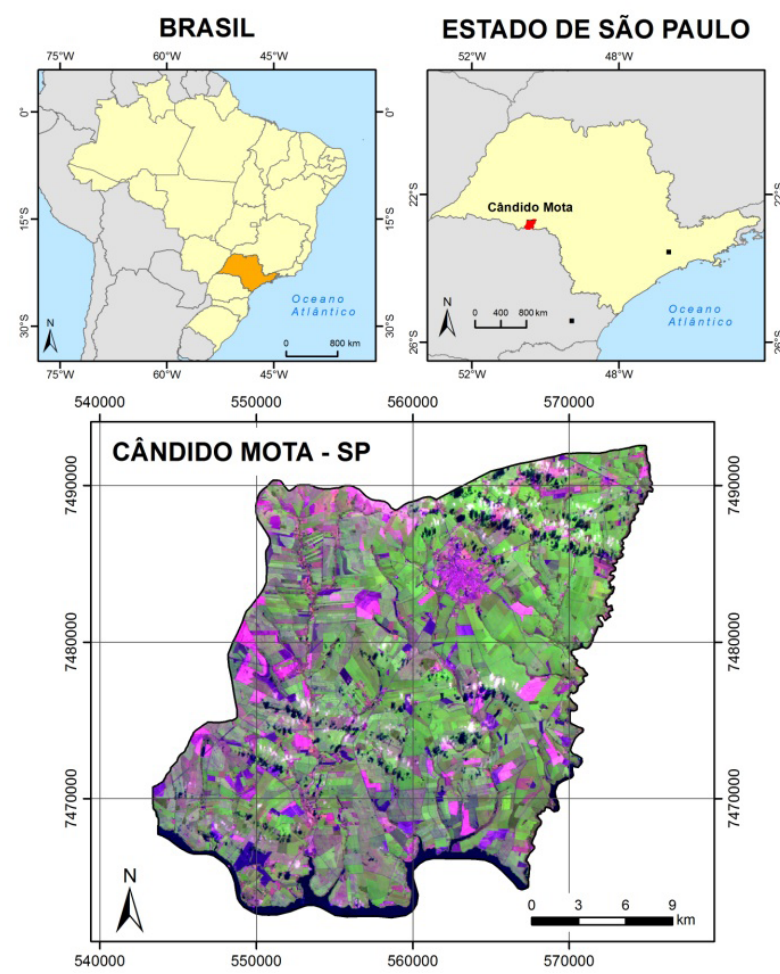

Figura 1 - Localização geográfica do município de Cândido Mota - SP 
De acordo com Ross e Moroz (1997), o município de Cândido Mota está contido na Bacia Sedimentar do Paraná, unidade morfoescultural "Planalto Ocidental Paulista" e unidade geomorfológica "Planalto CentroOcidental”, na qual predominam as formas de relevo denudacionais, cujo modelado constitui-se basicamente de colinas amplas e baixas com topos convexos. A altitude média do município é de $410 \mathrm{~m}$, situada entre $322 \mathrm{e}$ $583 \mathrm{~m}$. A declividade média, obtida a partir de dados SRTM, é de 4,2 \%. E cerca de $99 \%$ de sua área possui declividade inferior a $12 \%$.

Considerando os impactos agrícolas, econômicos e sociais negativos das geadas e a necessidade da adoção de novas metodologias de análise dos seus efeitos, este estudo teve como objetivo avaliar os efeitos das geadas ocorridas nos dias 28/06/2011 e 04/08/2011 na cobertura vegetal do município de Cândido Mota - SP por meio dos índices de vegetação NDVI (Índice de Vegetação por Diferença Normalizada) e NDWI (Índice de Água por Diferença Normalizada), com o apoio de técnicas de Geoprocessamento e Sensoriamento Remoto. O estudo também buscou verificar a influência da altitude na intensidade das geadas e nos danos resultantes à cobertura vegetal e às principais culturas agrícolas implantadas no município, além de avaliar a eficácia dos índices de vegetação na detecção das alterações provocadas por esses fenômenos climáticos na cobertura vegetal.

Material e métodos

\section{Materiais}

Para o desenvolvimento deste estudo foram utilizados os seguintes materiais:

- Cartas topográficas de escala 1:50.000, folhas: Assis (IBGE, 1975a), Cândido Mota (IBGE, 1975b), Florínia (IBGE, 1992a) e Maracaí (IBGE, 1992b);

- Imagens do satélite Landsat-5, sensor Thematic Mapper, órbita/ ponto 222/076, bandas $3(0,63-0,69 \mu \mathrm{m}), 4(0,76-0,90 \mu \mathrm{m})$ e 5 (1,55 - 1,75 $\mu \mathrm{m})$, de 28/05/2011, 15/07/2011 e 16/08/2011, obtidas do catálogo de imagens do INPE;

- Modelo numérico de elevação da missão de mapeamento do relevo terrestre SRTM (Shuttle Radar Topography Mission), de 90 metros de resolução espacial, obtido do banco de dados Brasil em Relevo 
da Embrapa Monitoramento por Satélite (Miranda, 2005);

- SIGs Idrisi Taiga (Eastman, 2009) e ArcGIS/ArcMap 10 (ESRI, 2011).

\section{Procedimentos metodológicos}

Este estudo seguiu as etapas metodológicas apresentadas abaixo:

- Aquisição dos dados e elaboração da base cartográfica

O limite do município de Cândido Mota foi vetorizado sobre as cartas topográficas que o compõem, as quais foram juntadas (mosaico), georreferenciadas no SIG Idrisi Taiga e convertidas para o datum horizontal SAD-69.

As imagens do satélite Landsat-5 Thematic Mapper, bandas 3, 4 e 5 , foram importadas e georreferenciadas no SIG Idrisi Taiga a partir dos pontos de controle extraídos das feições presentes nas cartas topográficas. Foram utilizadas as imagens de 28/05/2011 (última imagem disponível antes da ocorrência da primeira geada), 15/07/2011 (após a primeira geada) e 16/07/2014 (após a segunda geada).

O modelo numérico de elevação do terreno SRTM foi georreferenciado no SIG Idrisi Taiga, convertido do datum WGS-84 para o datum SAD-69 e reclassificado em seis classes hipsométricas, com intervalos de 50 metros.

\section{- Realização de trabalho de campo}

O trabalho de campo foi realizado na zona rural de Cândido Mota, no dia 13/08/2011, com o objetivo de identificar os danos causados pelas geadas nas culturas agrícolas e demais tipos de vegetação e auxiliar no mapeamento do uso da terra. Todas as classes de uso da terra foram visitadas, em locais previamente escolhidos e demarcados sobre as imagens Landsat de 28/05 e 15/07/2011, composição colorida falsa-cor 543, com destaque para as áreas de maior alteração visual provocada pelo fenômeno das geadas.

- Cálculo dos índices de vegetação e elaboração do mapa de uso da terra

Os índices de vegetação NDVI e NDWI foram calculados por meio do módulo "VEGINDEX" do SIG Idrisi Taiga. Para a elaboração do Índice de Vegetação por Diferença Normalizada (NDVI), foram utilizadas as bandas 
3 (vermelho) e 4 (infravermelho próximo), a partir da equação proposta por Rouse et al. (1973):

$$
N D V I=\frac{\rho_{\text {ivp }}-\rho_{v}}{\rho_{\text {ivp }}+\rho_{v}} N D V I=\frac{\rho_{\text {ivp }}-\rho_{v}}{\rho_{\text {ivp }}+\rho_{v}}
$$

Onde: $\rho_{i v p} \rho_{i v v}$ é o fluxo radiante refletido no infravermelho próximo (banda 4) e $\rho_{v} \rho_{v}$ é o fluxo radiante refletido no vermelho (banda 3).

O Índice de Água por Diferença Normalizada (NDWI) foi obtido a partir das bandas 4 (infravermelho próximo) e 5 (infravermelho médio) do satélite Landsat-5 TM, por meio da equação de Gao (1996):

$$
N D W I=\frac{\rho_{i v p}-\rho_{i v m}}{\rho_{i v p}+\rho_{i v m}} N D W I=\frac{\rho_{i v p}-\rho_{i v m}}{\rho_{\text {ivp }}+\rho_{\text {ivm }}}
$$

Onde: $\rho_{i v p} \rho_{i v v}$ é o fluxo radiante refletido no infravermelho próximo (banda 4) e $\rho_{i v m} \rho_{i v m}$ é o fluxo radiante refletido no infravermelho médio (banda 5).

Com a finalidade de se verificar a intensidade da variação dos índices NDVI e NDWI decorrente das geadas ocorridas, foram calculadas as "imagens diferença" de cada índice entre duas datas diferentes, sendo elas: a) [NDVI 15/07/2011] - [NDVI 28/05/2011]; b) [NDVI 16/08/2011 - NDVI 15/07/2011]; c) [NDVI 16/08/2011] - [NDVI 28/05/2011]. Os mesmos cálculos foram realizados para os índices NDWI.

O mapa de uso da terra de 28/05/2011 foi elaborado no SIG ArcMap 10, a partir da composição colorida falsa-cor 543, mediante análise visual e vetorização das classes de uso, a qual contou com o auxílio das imagens do Google Earth, de maior resolução espacial, para melhor identificação da forma das feições mapeadas, do trabalho de campo realizado no município e dos mapas de área cultivada com cana-de-açúcar em 2011 do Projeto Canasat (Rudorff, 2011). O uso da terra foi mapeado antes da ocorrência das geadas para possibilitar a análise dos danos provocados por este fenômeno em cada classe.

\section{- Análise estatística dos danos provocados pelas geadas}

As "imagens diferença" entre os índices NDVI e NDWI das diferentes datas foram associadas ao mapa de uso da terra de 28/05/2011 e analisadas estatisticamente por meio da ferramenta "ZONAL STATISTICS AS TABLE” do SIG ArcMap 10. Foram computados os parâmetros estatísticos 
das alterações nos referidos índices para cada classe de uso da terra, tais como média, desvio padrão e coeficiente de variação, para verificar a alteração média nos parâmetros biofísicos da vegetação e no conteúdo de água, decorrente das geadas, nas diferentes culturas agrícolas e classes de uso da terra. A mesma análise estatística foi realizada entre as "imagens diferença” e o mapa hipsométrico do município de Cândido Mota, a fim de verificar a influência da altitude e do relevo na intensidade das geadas e de seus efeitos sobre a cobertura vegetal.

As culturas agrícolas que tiveram as maiores alterações de NDVI e NDWI decorrentes das geadas e as de maior representatividade no município foram individualizadas e associadas aos intervalos de altitude em arquivos vetoriais, por meio da ferramenta "INTERSECT" do SIG ArcMap 10. Em seguida, foram associadas à "imagem diferença" de NDWI de 15/07/2011 por análise zonal (ferramenta "ZONAL STATISTICS AS TABLE”), com a finalidade de quantificar a influência da altitude na alteração do conteúdo de água nas respectivas culturas agrícolas resultante dos fenômenos meteorológicos ocorridos após a primeira geada (28/06/2011).

Por fim, foram realizadas a análise dos histogramas das imagens NDVI e NDWI no SIG Idrisi Taiga e a análise zonal entre algumas classes de uso da terra de diferentes densidades de cobertura vegetal e as "imagens diferença” de NDVI e NDWI no SIG ArcMap 10, buscando comparar a eficácia dos dois índices de vegetação na avaliação dos efeitos das geadas sobre a cobertura vegetal.

\section{Resultados e discussão}

O mapa de uso da terra do município de Cândido Mota de 28/05/2011 e as áreas das classes de uso da terra estão apresentados na Figura 2 e na Tabela 1.

Em maio de 2011, as principais culturas agrícolas implantadas no município de Cândido Mota eram o milho safrinha e a cana-de-açúcar, ambos cultivados em todos os compartimentos de relevo. As lavouras de cana-de-açúcar se concentravam nas regiões noroeste, oeste, sudoeste e sul do município e abasteciam as usinas de açúcar e álcool dos municípios vizinhos. Já as lavouras de milho possuíam maior concentração nas regiões nordeste, leste e sudeste do município. As áreas de solo exposto 
resultavam, em sua maioria, da colheita da cana-de-açúcar antes de 28 de maio, ou ainda do pousio de áreas ocupadas por soja ou milho no verão. Os demais cultivos, de menor expressão no município, eram café, trigo, aveia e pastagens.

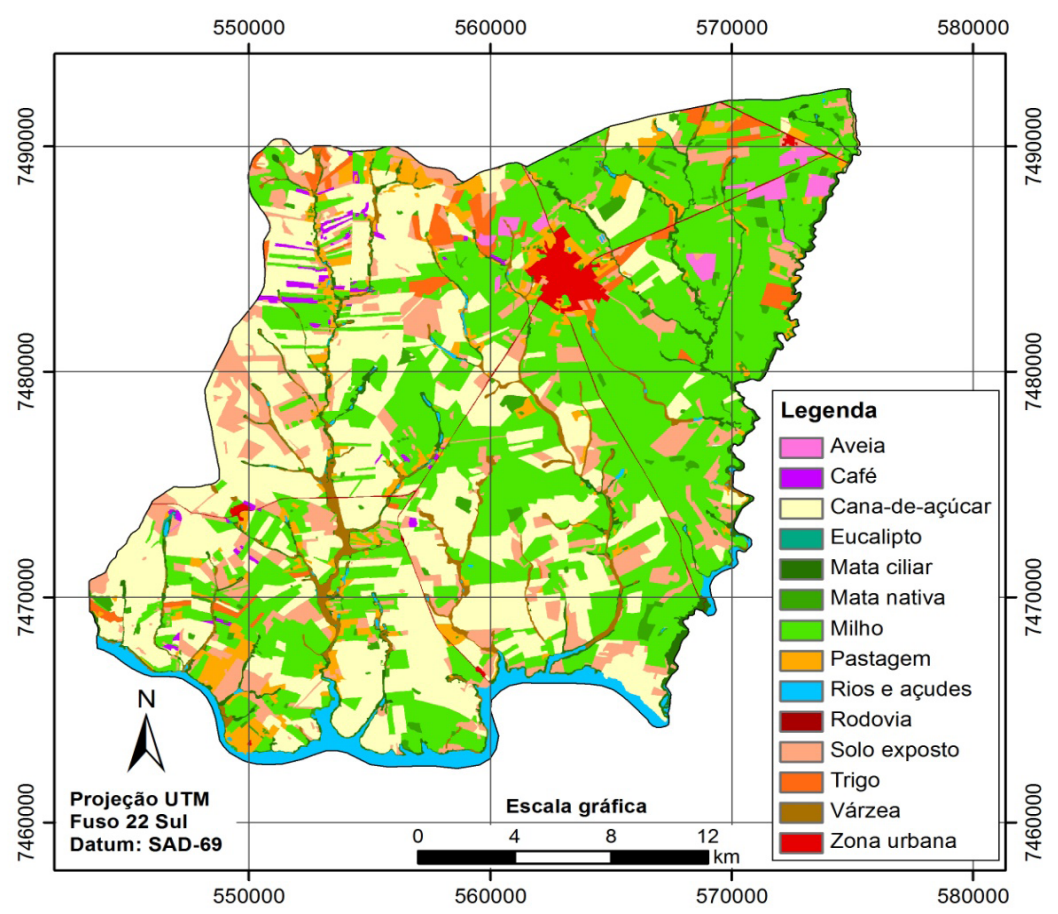

Figura 2 - Mapa de uso da terra do município de Cândido Mota - SP em 28 05/2011

As Tabelas 2 e 3 apresentam, respectivamente, as diferenças médias de valores de NDVI e NDWI obtidos entre as datas de 28/05/2011 (antes da primeira geada), 15/07/2011 (após a primeira geada) e 16/08/2011 (após a segunda geada) por classe de uso da terra, assim como o coeficiente de variação.

As áreas ocupadas por florestas naturais (mata nativa e mata ciliar) ou plantadas (eucalipto), de alta densidade de cobertura vegetal, tiveram redução de NDVI da ordem de -0,195 (mata nativa) a -0,225 (eucalipto), e de -0,233 (mata nativa) a -0,245 (mata ciliar) em valores NDWI de maio a agosto, denotando a redução do seu vigor vegetativo e conteúdo de água, mesmo não adquirindo o aspecto de folhas secas, conforme constatado em trabalho de campo. 
Tabela 1 - Área das classes de uso da terra do município de Cândido Mota - SP em 28/05/2011

\begin{tabular}{ccc}
\hline Classe de uso da terra & Área $\left(\mathrm{km}^{2}\right)$ & Área $(\%)$ \\
\hline Aveia & 5,75 & 0,93 \\
Café & 3,82 & 0,62 \\
Cana-de-açúcar & 184,26 & 29,90 \\
Eucalipto & 0,23 & 0,04 \\
Mata ciliar & 22,12 & 3,59 \\
Mata nativa & 10,95 & 1,78 \\
Milho & 238,54 & 38,71 \\
Pastagem & 27,65 & 4,49 \\
Rios e açudes & 18,73 & 3,04 \\
Rodovia & 2,53 & 0,41 \\
Solo exposto & 67,43 & 10,94 \\
Trigo & 12,69 & 2,06 \\
Várzea & 15,03 & 2,44 \\
Zona urbana & 6,54 & 1,06 \\
\hline Total & $\mathbf{6 1 6 , 2 8}$ & $\mathbf{1 0 0}$ \\
\hline
\end{tabular}

Fonte: Os Autores, 2015.

Tabela 2 - Diferenças de valores de NDVI por classe de uso da terra entre as datas 28/05, 15/07 e 16/08/2011: média e coeficiente de variação (CV)

\begin{tabular}{ccccccc}
\hline \multirow{2}{*}{$\begin{array}{c}\text { Classe de } \\
\text { uso da terra }\end{array}$} & \multicolumn{2}{c}{$\mathbf{2 8} / \mathbf{0 5}$ a $\mathbf{1 5 / 0 7 / 2 0 1 1}$} & \multicolumn{2}{c}{$\mathbf{1 5 / 0 7}$ a 16/08/2011 } & \multicolumn{2}{c}{$\mathbf{2 8 / 0 5}$ a 16/08/2011 } \\
\cline { 2 - 7 } & Média & $\mathbf{C V ~} \mathbf{2}$ ) & Média & CV (\%) & Média & CV (\%) \\
\hline Aveia & $-0,349$ & $-28,53$ & $-0,162$ & $-65,52$ & $-0,511$ & $-23,74$ \\
Café & $-0,180$ & $-71,04$ & $-0,045$ & $-232,22$ & $-0,225$ & $-60,83$ \\
Cana-de-açúcar & $-0,241$ & $-67,40$ & $-0,063$ & $-181,95$ & $-0,304$ & $-60,85$ \\
Eucalipto & $-0,093$ & $-125,65$ & $-0,120$ & $-142,35$ & $-0,225$ & $-73,99$ \\
Mata ciliar & $-0,187$ & $-75,12$ & $-0,037$ & $-436,64$ & $-0,224$ & $-77,95$ \\
Mata nativa & $-0,137$ & $-99,44$ & $-0,058$ & $-217,66$ & $-0,195$ & $-79,37$ \\
Milho & $-0,462$ & $-29,47$ & $-0,088$ & $-110,21$ & $-0,550$ & $-20,12$ \\
Pastagem & $-0,177$ & $-68,07$ & $-0,007$ & $-1484,57$ & $-0,184$ & $-72,90$ \\
Rios e açudes & $-0,043$ & $-318,65$ & 0,006 & $2.963,95$ & $-0,037$ & $-502,99$ \\
Rodovias & $-0,202$ & $-83,21$ & $-0,051$ & $-201,83$ & $-0,253$ & $-72,73$ \\
Solo exposto & $-0,066$ & $-205,59$ & 0,010 & 921,71 & $-0,056$ & $-268,78$ \\
Trigo & $-0,144$ & $-98,17$ & $-0,286$ & $-48,29$ & $-0,430$ & $-37,44$ \\
Várzea & $-0,210$ & $-61,31$ & $-0,004$ & $-3.263,22$ & $-0,214$ & $-72,81$ \\
Zona urbana & $-0,067$ & $-148,61$ & $-0,002$ & $-6.207,56$ & $-0,068$ & $-150,79$ \\
\hline
\end{tabular}

Fonte: Os Autores, 2015.

Considerando as diferenças de índices de vegetação, as culturas agrícolas mais afetadas pelas geadas em todo o período foram, em ordem decrescente, o milho safrinha, a aveia, o trigo e a cana-de-açúcar. Dados do Instituto de Economia Agrícola e da Coordenadoria de Assistência Técnica 
Integral (IEA/CATI) de setembro de 2011 disponibilizados pela CATI de Cândido Mota (Parise, 2012) mostram que a produtividade prevista para o milho safrinha em 2011 era de 60 sacas/hectare (sacas de $60 \mathrm{~kg}$ ), e que a produtividade obtida foi de 30 sacas/hectare em decorrência das geadas.

Tabela 3 - Diferenças de valores de NDWI por classe de uso da terra entre as datas 28/05, 15/07 e 16/08/2011: média e coeficiente de variação (CV)

\begin{tabular}{ccccccc}
\hline \multirow{2}{*}{$\begin{array}{c}\text { Classe de uso } \\
\text { da terra }\end{array}$} & $\mathbf{2 8 / 0 5}$ a $\mathbf{1 5 / 0 7 / 2 0 1 1}$ & \multicolumn{2}{c}{$\mathbf{1 5 / 0 7}$ a $\mathbf{1 6 / 0 8 / 2 0 1 1}$} & \multicolumn{2}{c}{$\mathbf{2 8 / 0 5}$ a 16/08/2011 } \\
\cline { 2 - 7 } & Média & $\mathbf{C V ~} \mathbf{2} \%$ & Média & CV (\%) & Média & CV (\%) \\
\hline Aveia & $-0,310$ & $-32,53$ & $-0,207$ & $-54,77$ & $-0,517$ & $-25,22$ \\
Café & $-0,205$ & $-65,24$ & $-0,045$ & $-223,77$ & $-0,250$ & $-56,73$ \\
Cana-de-açúcar & $-0,235$ & $-65,17$ & $-0,065$ & $-143,52$ & $-0,300$ & $-56,00$ \\
Eucalipto & $-0,113$ & $-140,22$ & $-0,128$ & $-142,27$ & $-0,241$ & $-68,87$ \\
Mata ciliar & $-0,193$ & $-76,69$ & $-0,052$ & $-250,82$ & $-0,245$ & $-68,56$ \\
Mata nativa & $-0,157$ & $-91,43$ & $-0,075$ & $-156,08$ & $-0,233$ & $-69,04$ \\
Milho & $-0,491$ & $-30,45$ & $-0,092$ & $-117,05$ & $-0,583$ & $-23,03$ \\
Pastagem & $-0,168$ & $-70,66$ & $-0,013$ & $-709,45$ & $-0,181$ & $-69,74$ \\
Rios e açudes & $-0,049$ & $-352,96$ & $-0,039$ & $-377,72$ & $-0,088$ & $-200,38$ \\
Rodovias & $-0,219$ & $-78,15$ & $-0,065$ & $-155,51$ & $-0,284$ & $-62,85$ \\
Solo exposto & $-0,063$ & $-210,86$ & 0,001 & $16.634,41$ & $-0,062$ & $-216,12$ \\
Trigo & $-0,093$ & $-176,66$ & $-0,288$ & $-47,35$ & $-0,381$ & $-42,85$ \\
Várzea & $-0,226$ & $-64,24$ & $-0,020$ & $-516,56$ & $-0,246$ & $-64,11$ \\
Zona urbana & $-0,058$ & $-181,18$ & $-0,007$ & $-1.096,97$ & $-0,065$ & $-157,16$ \\
\hline
\end{tabular}

Fonte: Os Autores, 2015.

Em relação à cana-de-açúcar, dados do IEA/CATI apontaram a produtividade de 76 toneladas/hectare na safra 2010/2011, sendo previsto o rendimento de 82 toneladas/hectare (Parise, 2012). Embora aparentemente a redução na produção tenha sido pequena, deve-se considerar que no período houve aumento na área colhida no município, que passou de 17.953 hectares em 2010 para 21.288 hectares em 2011, de acordo com os dados do Projeto Canasat.

Além disso, houve perda qualitativa no produto colhido em função da redução no ATR (Açúcar Total Recuperável por unidade de área) da cana-de-açúcar, resultando em menor rendimento industrial (Parise, 2012). Deve-se considerar ainda que a colheita da cana-de-açúcar começou antes da ocorrência das geadas, o que também pode ter influenciado os resultados finais relativos a essa cultura.

Os coeficientes de variação elevados das médias de diferenças de NDVI e NDWI, alguns superiores a $100 \%$, mostram a heterogeneidade da 
mudança dos referidos índices, em todo o período em relação aos valores médios das classes de uso da terra, o que pode estar relacionado ao ciclo das culturas implantadas em diferentes épocas, à resistência às geadas e ao relevo. Os CVs (coeficientes de variação) elevados das áreas de solo exposto denotam as alterações no conteúdo de matéria orgânica (restos culturais) e de umidade no solo de maio a agosto, ou a implantação de novos cultivos e reforma de canaviais ao longo do período.

As culturas "milho" e "aveia" apresentaram os menores valores de CV, o que denota a menor variabilidade das diferenças de NDVI e NDWI e a homogeneidade do efeito das geadas sobre estas culturas. Os CVs elevados entre julho e agosto, a maioria acima de $100 \%$, decorrem da pequena alteração média de NDVI e NDWI das classes de uso da terra (-0,065 e -0,078, respectivamente), provavelmente em função dos maiores efeitos sobre a cobertura vegetal terem ocorrido após a geada de 28/06, cuja intensidade foi maior.

A Figura 3 apresenta as "imagens diferença" de NDVI (a) e NDWI (b) entre as datas 28/05/2011 e 15/07/2011.
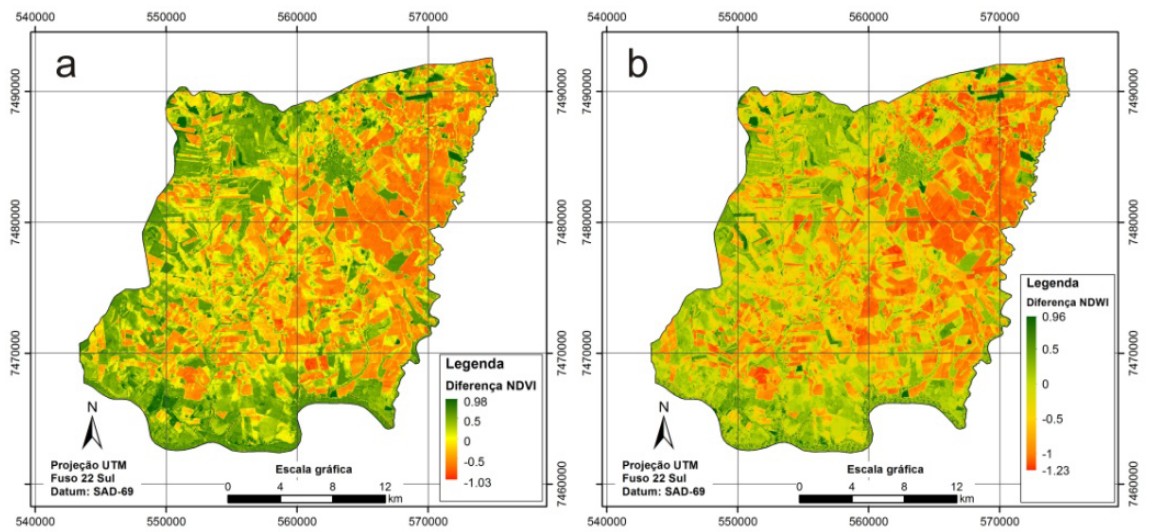

Figura 3 - Diferença de valores de NDVI (a) e NDWI (b) entre os dias 28/05/2011 e 15/07/2011 no município de Cândido Mota - SP

A comparação entre as alterações nos índices de vegetação e o mapa de uso da terra de 28/05/2011 mostra que as principais reduções ocorreram na cultura de milho, sobretudo nas áreas localizadas na região central e nordeste do município. Algumas áreas de solo exposto sofreram aumento 
nos valores absolutos dos índices de vegetação, pois tiveram a rebrota da cana-de-açúcar ou foram ocupadas por outros cultivos após a geada de 28/06. Parte das áreas cultivadas com cana-de-açúcar sofreu menor impacto das geadas devido à posição no relevo ou período de plantio e apresentou pequena redução de NDVI e NDWI entre maio e julho.

O mapa hipsométrico do município de Cândido Mota pode ser observado na Figura 4. As maiores altitudes estão situadas na região norte e reduzem em direção ao sul do município, que é banhado pelo Rio Paranapanema.

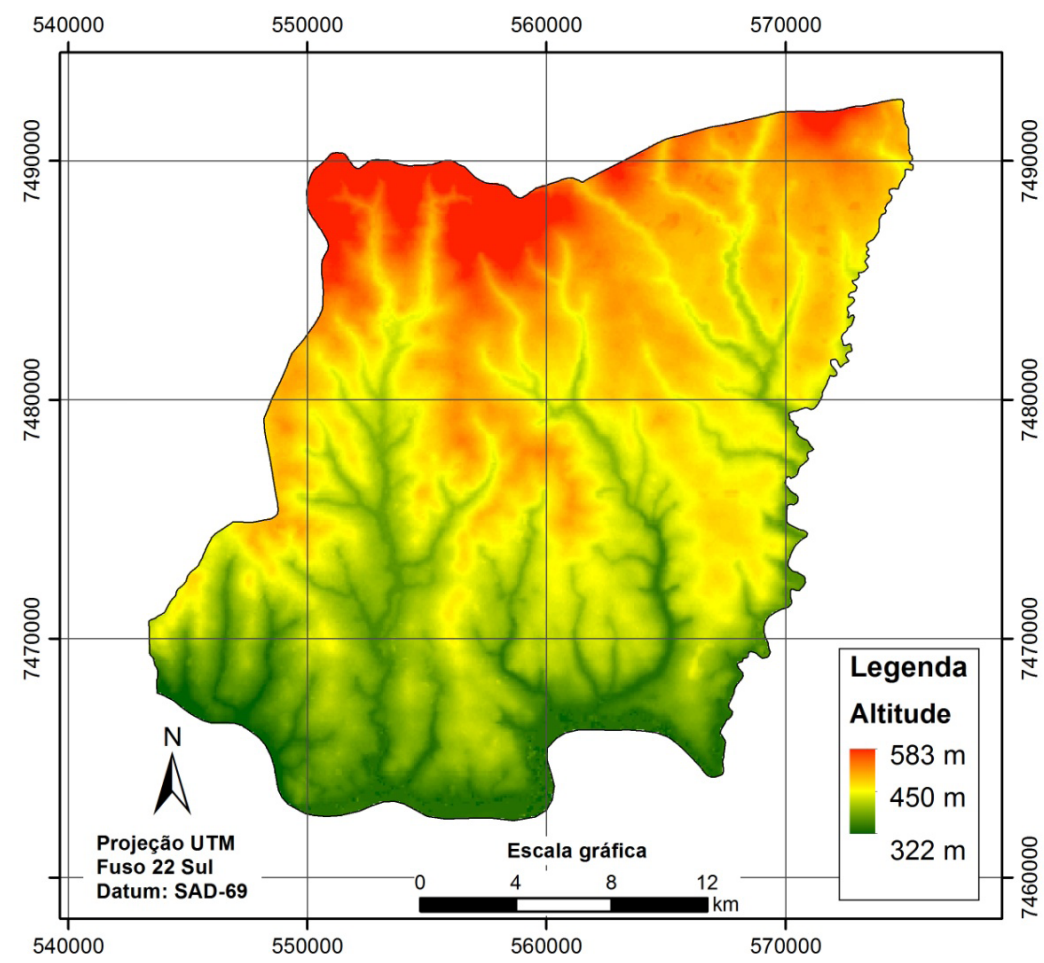

Figura 4 - Hipsometria do município de Cândido Mota - SP a partir de dados Shuttle Radar Topography Mission (SRTM)

As Tabelas 4 e 5 apresentam as médias e coeficientes de variação das alterações de NDVI e NDWI, respectivamente, nas diferentes classes 
hipsométricas do município de Cândido Mota entre as datas 28/05, 15/07 e 16/08/2011.

Os dados das tabelas mostram que os principais efeitos das geadas de 28/06 e 04/08/2011, na cobertura vegetal de Cândido Mota, ocorreram entre as altitudes de 400 a 500 metros, classes intermediárias de altitude do município, seguidas da altitude entre 350 e 400 metros. Nas áreas mais elevadas, a maior exposição à radiação solar e o transporte do ar frio para as vertentes e fundos de vale fazem com que a temperatura da relva seja mais elevada, a perda de radiação seja menor que nos demais compartimentos de relevo e a intensidade das geadas, consequentemente, também seja menor.

Tabela 4 - Diferenças de valores de NDVI por classe hipsométrica entre as datas 28/05, 15/07 e 16/08/2011: média e coeficiente de variação (CV)

\begin{tabular}{|c|c|c|c|c|c|c|}
\hline \multirow{2}{*}{ Altitude } & \multicolumn{2}{|c|}{$\begin{array}{c}28 / 05 / 2011 \text { a } \\
15 / 07 / 2011\end{array}$} & \multicolumn{2}{|c|}{$\begin{array}{c}15 / 07 / 2011 \text { a } \\
16 / 08 / 2011\end{array}$} & \multicolumn{2}{|c|}{$\begin{array}{c}28 / 05 / 2011 \text { a } \\
16 / 08 / 2011\end{array}$} \\
\hline & Média & CV (\%) & Média & CV (\%) & Média & CV (\%) \\
\hline 322 - $350 \mathrm{~m}$ & $-0,087$ & $-139,46$ & $-0,006$ & $-3.147,89$ & $-0,093$ & $-231,58$ \\
\hline $350-400 \mathrm{~m}$ & $-0,209$ & $-92,63$ & $-0,046$ & $-296,22$ & $-0,255$ & $-90,20$ \\
\hline $400-450 \mathrm{~m}$ & $-0,335$ & $-57,39$ & $-0,049$ & $-204,28$ & $-0,384$ & $-56,42$ \\
\hline $450-500 \mathrm{~m}$ & $-0,330$ & $-63,58$ & $-0,076$ & $-153,87$ & $-0,405$ & $-57,23$ \\
\hline $500-550 \mathrm{~m}$ & $-0,178$ & $-97,65$ & $-0,130$ & $-117,65$ & $-0,308$ & $-73,01$ \\
\hline $550-583 \mathrm{~m}$ & $-0,147$ & $-118,51$ & $-0,073$ & $-181,54$ & $-0,219$ & $-103,11$ \\
\hline
\end{tabular}

Fonte: Os Autores, 2015.

Tabela 5- Diferenças de valores de NDWI por classe de altitude entre as datas 28/05, 15/07 e 16/08/2011: média e coeficiente de variação (CV)

\begin{tabular}{|c|c|c|c|c|c|c|}
\hline \multirow{2}{*}{ Altitude } & \multicolumn{2}{|c|}{$\begin{array}{c}28 / 05 / 2011 \text { a } \\
15 / 07 / 2011\end{array}$} & \multicolumn{2}{|c|}{$\begin{array}{c}15 / 07 / 2011 \text { a } \\
16 / 08 / 2011\end{array}$} & \multicolumn{2}{|c|}{$\begin{array}{c}28 / 05 / 2011 \text { a } \\
16 / 08 / 2011\end{array}$} \\
\hline & Média & CV (\%) & Média & CV (\%) & Média & CV (\%) \\
\hline $322-350 \mathrm{~m}$ & $-0,087$ & $-199,59$ & $-0,057$ & $-258,04$ & $-0,144$ & $-138,29$ \\
\hline $350-400 \mathrm{~m}$ & $-0,214$ & $-92,84$ & $-0,053$ & $-227,12$ & $-0,267$ & $-82,04$ \\
\hline $400-450 \mathrm{~m}$ & $-0,343$ & $-60,12$ & $-0,053$ & $-174,97$ & $-0,396$ & $-56,91$ \\
\hline $450-500 \mathrm{~m}$ & $-0,342$ & $-67,18$ & $-0,084$ & $-137,21$ & $-0,426$ & $-58,52$ \\
\hline
\end{tabular}




\begin{tabular}{lllllll}
$\mathbf{5 0 0}-\mathbf{5 5 0} \mathbf{~ m}$ & $-0,181$ & $-95,35$ & $-0,140$ & $-106,97$ & $-0,321$ & $-71,35$ \\
$\mathbf{5 5 0}-\mathbf{5 8 3} \mathbf{m}$ & $-0,155$ & $-109,97$ & $-0,085$ & $-148,39$ & $-0,240$ & $-91,42$ \\
\hline
\end{tabular}

Fonte: Os Autores, 2015.

Embora as geadas ocorram com maior frequência nos fundos de vale e depressões em função do acúmulo de ar frio, mais denso e canalizado pelas vertentes, no caso da área estudada, as menores altitudes estão localizadas nas proximidades do reservatório da usina hidrelétrica Canoas I no Rio Paranapanema, o que faz com que seus efeitos sejam amenizados, pois durante as horas de sol, a energia disponível nos ambientes de represas é empregada para a mudança de estado físico da água do reservatório. O vapor de água gerado, retido próximo à superfície nas camadas mais baixas da atmosfera, impede ou reduz a perda de radiação, minimizando a ocorrência das geadas e de danos à vegetação.

Os CVs de NDVI e NDWI foram menores nas altitudes médias, denotando que os efeitos das geadas tiveram maior uniformidade nesta faixa de altitude. Já nas classes inferiores e superiores de altitude, os diferentes tipos de vegetação devem ter sofrido os efeitos de maneira desigual, o que justifica a maior variabilidade nos índices analisados.

A Tabela 6 mostra que a média e o desvio padrão das "imagens diferença” NDVI e NDWI dos mesmos períodos são semelhantes, o que denota a similaridade entre os dois índices na detecção de mudanças na cobertura vegetal em decorrência das geadas, mesmo tendo sido concebidos para monitorar diferentes parâmetros biofísicos da vegetação. A análise das imagens NDVI e NDWI das três datas para algumas culturas agrícolas de diferentes densidades de cobertura do solo também demonstrou que os dois índices possuem desvios padrões similares, apesar de médias diferentes para cada cultura, sendo a média dos valores de NDVI, em geral, maior.

Tabela 6 - "Imagens diferença" de NDVI e NDWI: média, desvio padrão, coeficiente de variação, valores mínimos e máximos e intervalos

\begin{tabular}{ccccccc}
\hline “Imagens diferença" & Média & DP & CV (\%) & Valor min & Valor máx & Intervalo \\
\hline NDVI - 28/05 a 15/07 & $-0,291$ & 0,207 & $-71,13$ & $-1,033$ & 0,989 & 2,022 \\
NDWI - 28/05 a 15/07 & $-0,299$ & 0,221 & $-73,91$ & $-1,238$ & 0,964 & 2,202 \\
NDVI - 28/05 a 16/08 & $-0,353$ & 0,235 & $-66,57$ & $-1,241$ & 1,160 & 2,401
\end{tabular}




\begin{tabular}{ccccccc}
\hline “Imagens diferença" & Média & DP & CV (\%) & Valor min & Valor máx & Intervalo \\
\hline NDWI - 28/05 a 16/08 & $-0,368$ & 0,242 & $-65,76$ & $-1,214$ & 1,018 & 2,232 \\
NDVI - 15/07 a 16/08 & $-0,062$ & 0,122 & $-196,77$ & $-1,168$ & 1,079 & 2,247 \\
NDWI - 15/07 a 16/08 & $-0,069$ & 0,115 & $-166,67$ & $-0,812$ & 0,807 & 1,619 \\
\hline
\end{tabular}

Fonte: Os Autores, 2015.

Dos demais parâmetros estatísticos da Tabela 6, apenas as "imagens diferença” do período de 15/07 a 16/08/2011 apresentaram resultados diferentes de CV, valores mínimos e máximos e intervalos, provavelmente devido às menores variações dos índices, já que as maiores alterações ocorreram após a geada de 28/06/2011, ou em razão da colheita de algumas culturas. Assim, infere-se que os índices NDVI e NDWI tiveram a mesma eficácia na avaliação dos efeitos das geadas na cobertura vegetal.

Os parâmetros estatísticos das diferenças de NDWI para a análise das culturas milho, cana-de-açúcar e aveia no período de 28/05 a 15/07/2011, segundo as classes hipsométricas são apresentados na Tabela 7.

Tabela 7 - Diferenças de valores NDWI por classe hipsométrica entre as datas 28/05 e 15/07/2011 para milho, cana-de-açúcar e aveia: média e coeficiente de variação

\begin{tabular}{ccccccc}
\hline \multirow{2}{*}{ Altitude } & \multicolumn{2}{c}{ Milho } & \multicolumn{2}{c}{ Cana-de-açúcar } & \multicolumn{2}{c}{ Aveia } \\
\cline { 2 - 7 } & Média & CV (\%) & Média & CV (\%) & Média & CV (\%) \\
\hline $\mathbf{3 2 2}-\mathbf{3 5 0} \mathbf{~ m}$ & $-0,239$ & $-47,98$ & $-0,225$ & $-77,43$ & - & - \\
$\mathbf{3 5 0}-\mathbf{4 0 0} \mathbf{~ m}$ & $-0,419$ & $-40,12$ & $-0,197$ & $-76,38$ & $-0,234$ & $-37,51$ \\
$\mathbf{4 0 0}-\mathbf{4 5 0} \mathbf{~ m}$ & $-0,523$ & $-24,22$ & $-0,278$ & $-50,38$ & $-0,312$ & $-30,86$ \\
$\mathbf{4 5 0}-\mathbf{5 0 0} \mathbf{~}$ & $-0,510$ & $-27,08$ & $-0,222$ & $-67,28$ & $-0,227$ & $-37,12$ \\
$\mathbf{5 0 0}-\mathbf{5 5 0} \mathbf{~}$ & $-0,292$ & $-51,64$ & $-0,136$ & $-110,64$ & - & - \\
$\mathbf{5 5 0}-\mathbf{5 8 3} \mathbf{~ m}$ & $-0,293$ & $-43,26$ & $-0,192$ & $-93,92$ & - & - \\
\hline
\end{tabular}

Fonte: Os Autores, 2015.

Os resultados apontam, para a cultura do milho, a maior redução de NDWI nas altitudes médias, de $350 \mathrm{~m}$ a $500 \mathrm{~m}$, provavelmente em função do efeito do reservatório Canoas I na amenização do fenômeno nas altitudes menores e da menor intensidade da geada nas maiores altitudes. A cultura da cana-de-açúcar teve maior redução de NDWI na altitude de 400 a $450 \mathrm{~m}$, mas também sofreu consideravelmente os efeitos da 
geada em todas as classes de altitude, sendo o efeito relativamente menor apenas na classe de 500 a $550 \mathrm{~m}$. Mesmo assim, seu coeficiente de variação foi elevado. A aveia, não cultivada na menor e nas maiores classes de altitude, apresentou maior alteração de NDWI na altitude entre 400 e 450 $\mathrm{m}$, tendência também apresentada pelas demais culturas.

\section{Considerações finais}

A aplicação dos índices NDVI e NDWI no município de Cândido Mota - SP permitiu inferir os danos causados pelas geadas de 28/06 e 04/08/2011 em sua cobertura vegetal, sendo as principais culturas agrícolas afetadas o milho safrinha, a aveia, o trigo e a cana-de-açúcar, em ordem decrescente. As florestas naturais e plantadas, café, pastagem e vegetação de várzea tiveram menor alteração nos índices utilizados. As maiores reduções de NDVI e NDWI foram verificadas após a primeira geada, ocorrida em 28/06/2011.

O efeito das geadas foi maior nas altitudes médias do município (400 a 500 metros) devido à influência do reservatório nas áreas de menor altitude, que amenizou os impactos, e da maior radiação solar e transporte do ar frio das maiores altitudes, que diminuíram a intensidade das geadas nesses locais.

Os índices NDVI e NDWI apresentaram desempenho semelhante na detecção dos efeitos das geadas no vigor vegetativo e no conteúdo de água do dossel, sendo o seu uso recomendado para estudos futuros sobre os impactos desses fenômenos. Recomenda-se também a análise dos efeitos das geadas em culturas agrícolas específicas em função de sua data de plantio e estágio fenológico, a partir de índices de vegetação.

\section{Referências}

CECCATO, P.; FLASSE, S.; GRÉGOIRE, J. M. Designing a spectral index to estimate vegetation water content from remote sensing data. Part 2. Validation and applications. Remote Sensing of Environment, New York, v. 82, n. 2-3, 2002. p. 198-207. Disponível em: <http://www.sciencedirect.com/science/article/pii/ S0034425702000366>. Acesso em: 13 jun. 2014.

EASTMAN, J. R. Idrisi Taiga - GIS and Image Processing Software - version 16. Worcester: Clark Labs, Clark University, 2009.

ESRI. ArcGIS Desktop: Release 10. Redlands: Environmental Systems Research Institute, 2011. 
GAO, B. C. NDWI - A Normalized Difference Water Index for remote sensing of vegetationliquid waterfromspace.RemoteSensingofEnvironment,NewYork, v.58,n. 3, 1996. p. 257-266. Disponível em: <ftp:/ftp.eri.ucsb.edu/pub/org/swim/WTLDS/ Encylopedia_Wetlands/papers/Gao_1996_NDWI.pdf>. Acesso em: 15 abr. 2014. IBGE. Superintendência de Cartografia. Carta topográfica: folha Assis - SF.22-ZA-V-1. Rio de Janeiro: Serviço Gráfico do IBGE, 1975a. Escala 1:50.000.

. Superintendência de Cartografia. Carta topográfica: folha Cândido Mota - SF.22-Z-A-V-3. Rio de Janeiro: Centro de Serviços Gráficos do IBGE, 1975b. Escala 1:50.000.

Diretoria de Geociências. Carta topográfica: folha Florínia - SF.22-Z-AIV-4. Rio de Janeiro: IBGE, 1992a. Escala: 1:50.000.

Diretoria de Geociências. Carta topográfica: folha Maracaí - SF.22-Z-AIV-2. Rio de Janeiro: IBGE, 1992b. Escala: 1:50.000.

Cândido Mota. Dados do Censo Demográfico, 2010. Disponível em: <http://www.cidades.ibge.gov.br/xtras/perfil.php?lang=\&codmun=351000\&sea rch=sao-paulo|candido-mota $>$. Acesso em: 23 maio 2014.

JACKSON, T. T.; CHEN, D.; COSH, M.; LI, F.; ANDERSON, M.; WALTHALL, C.; DORIASWAMY, P.; HUNT, E. R. Vegetation water content mapping using Landsat data derived normalized difference water index for corn and soybeans. Remote Sensing of Environment, New York, v. 92, n. 4, 2004. p. 475-482. Disponível em: <http://www.sciencedirect.com/science/article/pii/S0034425703003353>. Acesso em: 13 jun. 2014.

JENSEN, J. R. Sensoriamento Remoto da Vegetação. In: Sensoriamento Remoto do Ambiente: uma perspectiva em recursos terrestres. São José dos Campos: Parêntese, 2009. p. 357-410.

MIRANDA, E. E. de; (Coord.). Brasil em relevo. Campinas: Embrapa Monitoramento por Satélite, 2005. Disponível em: <http://www.relevobr.cnpm. embrapa.br>. Acesso em: 14 maio 2014.

MIRANDA, M. J.; PINTO, H. S.; ZULLO JR., J.; FAGUNDES, R. M.; FONSECHI, D. B.; CAlVE, L.; PELlEGRINO, G. Q. Clima dos municípios paulistas. São Paulo: CEPAGRI/UNICAMP, 2005. Disponível em: <http://www.cpa.unicamp. br/outras-informacoes/clima-dos-municipios-paulistas.html>. Acesso em: 31 maio 2014.

MOTA, F. S. Geada e plantas cultivadas. In: Meteorologia agrícola. São Paulo: Nobel, 1975. p. 200-227.

PARISE, S. L. sandro.parise@cati.sp.gov.br. Informações sobre produtividade. 22 fev. 2012. Mensagem enviada para: Edson Luís Piroli. elp@ourinhos.unesp. br.

PETSCH, C.; BUENO, M. B. Aplicação da técnica de NDVI em imagens Landsat para análise do efeito de geadas no município de Maringá - PR. In: SIMPÓSIO BRASILEIRO DE SENSORIAMENTO REMOTO, 16., 2013, Foz do Iguaçu - PR. Simpósio Brasileiro de Sensoriamento Remoto. Anais... Foz do Iguaçu: MCT/ 
INPE, 2013. p. 13-119. Disponível em: <http://www.dsr.inpe.br/sbsr2013/files/ p1502.pdf>. Acesso em: 8 jun. 2014.

RAFAELLI, D. R.; CAMPOS, S.; MOREIRA, M. A.; FARIA, R. T. Imagens TERRA/MODIS para verificação do impacto de geadas na região cafeeira de Cornélio Procópio, Paraná. Revista Energia na Agricultura, Botucatu, v. 21, n. 2, p. 33-44, 2006. Disponível em: <http://200.145.140.50/html/CD_REVISTA ENERGIA_vol6/vol21n22006/artigos/Debora\%20Rosa\%20Rafaelli.pd̄f $>$. Acesso em: 27 maīo 2014.

ROSS, J. L. S.; MOROZ, I. C. Mapa Geomorfológico do Estado de São Paulo. São Paulo: FFLCH-USP, 1997. Escala: 1:500.000.

ROUSE, J. W.; HAAS, R. H.; SCHELL, J. A.; DEERING, D. W. Monitoring the vernal advancement and retrogradation (green wave effect) of natural vegetation. Greenbelt: Goddard Space Flight Center, 1973. 120 p. (Type II Report for Period September 1972 - March 1973).

RUDORFF, B. F. T. (Coord.). Projeto Canasat: Monitoramento da Cana-de-açúcar via imagens de satélite. São José dos Campos: Instituto Nacional de Pesquisas Espaciais, 2011. Disponível em: <http://www.dsr.inpe.br/laf/canasat/>. Acesso em: 10 jun. 2014.

SERRA, E. Reflexões sobre a origem da crise agrária no norte do Paraná. Boletim de Geografia, Maringá, v. 19, n. 1, 2001. p. 45-58. Disponível em: <http:// www.periodicos.uem.br/ojs/index.php/BolGeogr/article/view/12861/7278>. Acesso em: 14 jun. 2014.

Julio Cesar Demarchi - Possui Graduação em Geografia pela Universidade Estadual Paulista. Mestrado em Agronomia pela Universidade Estadual Paulista. Atualmente é Doutorando em Geografia pela mesma Universidade.

Edson Luís Piroli - Possui Graduação em Engenharia Florestal pela Universidade Federal de Santa Maria. Mestrado em Engenharia Agrícola pela mesma Universidade e Doutorado em Agronomia pela Universidade Estadual Paulista. Atualmente é Professor Adjunto da Universidade Estadual Paulista. 